\title{
Design and Biological Evaluation of Lipoprotein-Based Donepezil Nanocarrier for Enhanced Brain Uptake through Oral Delivery
}

Kowthavarapu Venkata Krishna ${ }^{\mathrm{a}}$, Geetika Wadhwa ${ }^{\mathrm{a}}$, Amit Alexander ${ }^{\mathrm{b}}$, Neha Konija ${ }^{\mathrm{c}}$, Ranendra Narayana Saha ${ }^{\mathrm{d}}$, Ritushree Kukretic ${ }^{\mathrm{c}}$, Gautam Singhvia ${ }^{\mathrm{a}}$, Sunil Kumar Dubey ${ }^{\text {** }}$

a Department of Pharmacy, Birla Institute of Technology and Science, Pilani (BITS-PILANI), Pilani Campus, Rajasthan, India

${ }^{b}$ Department of Pharmaceutics, Rungta College of Pharmaceutical Sciences and Research, Bhilai, Chhattisgarh, India

${ }^{c}$ Genomics and Molecular Medicine Unit, CSIR-Institute of Genomics and Integrative Biology (CSIR-IGIB) Delhi - India

${ }^{d}$ Department of Biotechnology, Birla Institute of Technology and Science, Pilani (BITS-PILANI), Dubai Campus, Dubai - United Arab Emirates

\section{Supplementary Data}

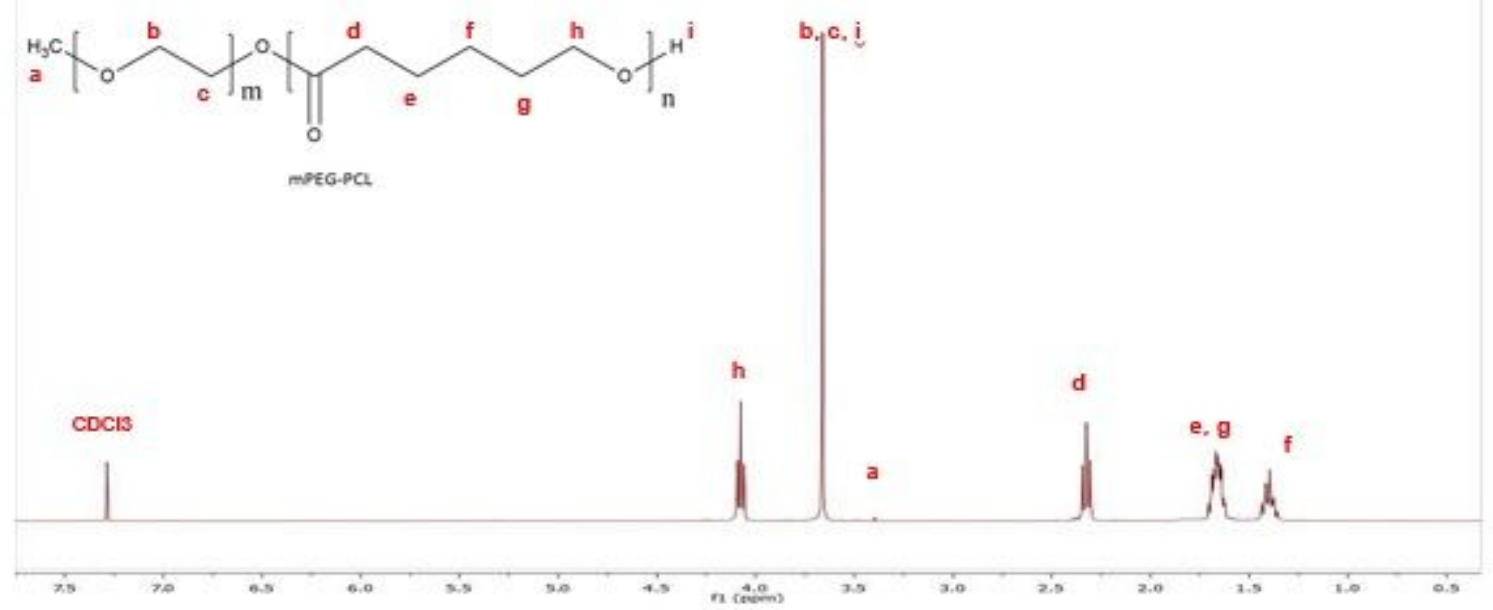

Figure S1: H-NMR data of mPEG-PCL

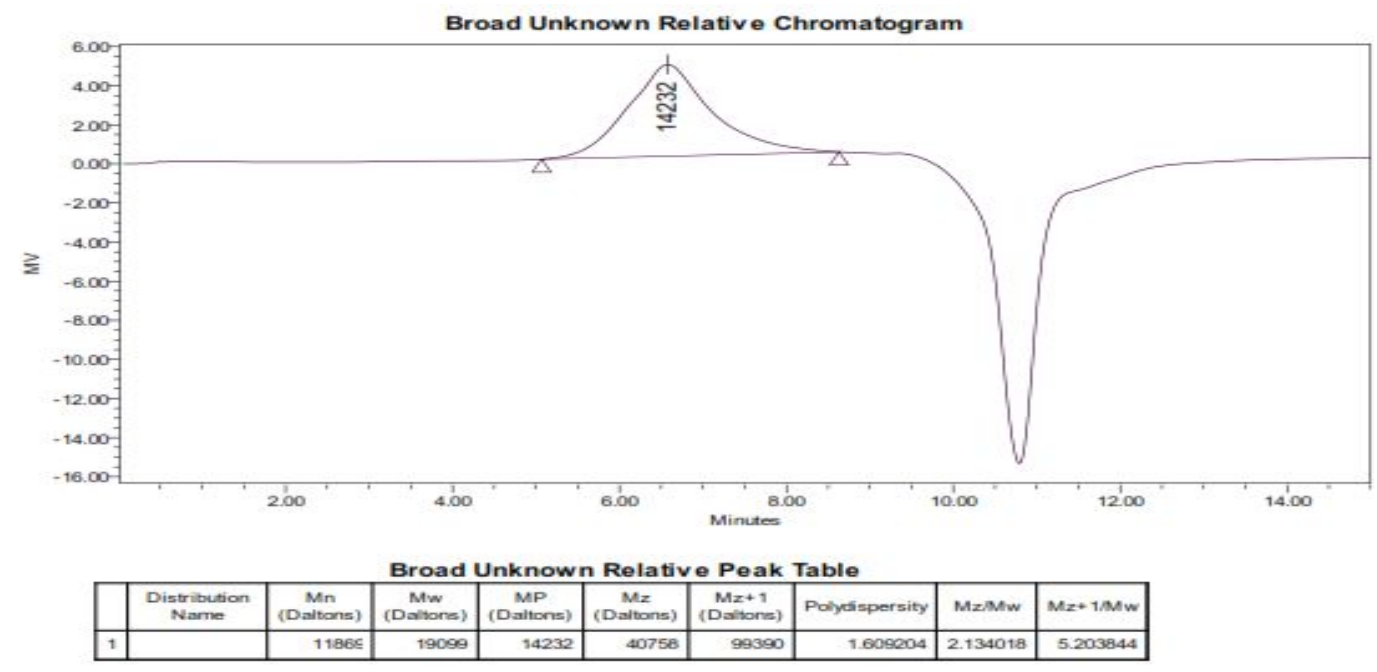


Figure S2: GPC data of mPEG-PCL

\begin{tabular}{ccccccc}
\hline Factor & Independent Factor & \multicolumn{5}{c}{ Levels } \\
\cline { 3 - 7 } Code & -1.414 & $\mathbf{- 1}$ & $\mathbf{0}$ & $\mathbf{1}$ & $\mathbf{1 . 4 1 4}$ \\
\hline $\mathrm{A}$ & $\begin{array}{c}\text { Drug:Polymer ratio } \\
(\mathrm{w} / \mathrm{w})\end{array}$ & 0.1 & 0.25 & 0.5 & 0.75 & 0.9 \\
$\mathrm{~B}$ & $\begin{array}{c}\text { Solvent:Non-Solvent } \\
\text { ratio (v/v) }\end{array}$ & 0.02 & 0.1 & 0.25 & 0.4 & 0.48 \\
\hline
\end{tabular}

Table S1: Levels of Independent factors used in the design 
Table S2: Central Composite Design for the optimization of nano-formulation

\begin{tabular}{ccc}
\hline $\begin{array}{c}\text { Formulation } \\
\text { Code }\end{array}$ & $\begin{array}{c}\text { Drug:Polymer } \\
\text { ratio }(\mathrm{w} / \mathrm{w})\end{array}$ & $\begin{array}{c}\text { Solvent:Non- } \\
\text { Solvent ratio } \\
\text { (v/v) }\end{array}$ \\
\hline F1 & 0.1 & 0.25 \\
F2 & 0.25 & 0.4 \\
F3 & 0.25 & 0.1 \\
F4 & 0.5 & 0.25 \\
F5 & 0.5 & 0.25 \\
F6 & 0.5 & 0.25 \\
F7 & 0.5 & 0.25 \\
F8 & 0.5 & 0.25 \\
F9 & 0.5 & 0.02 \\
F10 & 0.5 & 0.48 \\
F11 & 0.75 & 0.1
\end{tabular}




\begin{tabular}{lcc} 
F12 & 0.75 & 0.4 \\
F13 & 0.9 & 0.25 \\
\hline
\end{tabular}

\section{Supporting Information S1: Particle size (nm)}

The software suggested the quadratic model, for the particle size response based on the statistical significance and model maximizing the adjusted $\mathrm{R}^{2}$ and the predicted $\mathrm{R}^{2}$.

\begin{tabular}{ccccc}
\hline Source & $\begin{array}{c}\text { Sequential } \\
\text { p-value }\end{array}$ & $\begin{array}{c}\text { Lack of } \\
\text { Fit p-value }\end{array}$ & $\begin{array}{c}\text { Adjusted R- } \\
\text { Squared }\end{array}$ & $\begin{array}{c}\text { Predicted R- } \\
\text { Squared }\end{array}$ \\
\hline Linear & 0.0471 & $<0.0001$ & 0.3488 & 0.0571 \\
2FI & 0.7573 & $<0.0001$ & 0.2845 & -0.0795 \\
Quadratic & $<\mathbf{0 . 0 0 0 1}$ & $\mathbf{0 . 1 4 2 3}$ & $\mathbf{0 . 9 9 4 9}$ & $\mathbf{0 . 9 8 3 7 ^ { * }}$ \\
Cubic & 0.0523 & 0.6590 & 0.9978 & 0.9953 \\
\hline
\end{tabular}

suggested

Analysis of variance table for Response Surface Quadratic Model 


\begin{tabular}{cccccc}
\hline Source & Sum of Squares & df & Mean Square & F Value & $\begin{array}{c}\text { Prob }>\text { F } \\
\text { p-value }\end{array}$ \\
\hline Model & 110781.01 & 5 & 22156.20 & 469.19 & $<0.0001^{\ddagger}$ \\
A-A & 1021.60 & 1 & 1021.60 & 21.63 & 0.0023 \\
B-B & 32952.04 & 1 & 32952.04 & 697.80 & $<0.0001$ \\
AB & 672.62 & 1 & 672.62 & 14.24 & 0.0069 \\
$\mathrm{~A}^{\wedge} 2$ & 11511.05 & 1 & 11511.05 & 243.76 & $<0.0001$ \\
$\mathrm{~B}^{\wedge} 2$ & 55865.86 & 1 & 55865.86 & 1183.04 & $<0.0001$ \\
Residual & 330.56 & 7 & 47.22 & & \\
Lack of Fit & 234.42 & 3 & 78.14 & 3.25 & $0.1423^{\ddagger}$ \\
Pure Error & 96.13 & 4 & 24.03 & & \\
Cor Total & 111111.57 & 12 & & & \\
\hline : Drug:Polymer ratio $(\mathrm{w} / \mathrm{w})$, B: Solvent:Non-Solvent ratio $(\mathrm{v} / \mathrm{v}))^{¥}$ significant and ${ }^{\mathfrak{f}}$ not significant
\end{tabular}

Where, A: Drug:Polymer ratio (w/w), B: Solvent:Non-Solvent ratio (v/v), ${ }^{¥}$ significant and ${ }^{\mathfrak{E}}$ not significant

The Model F-value of 469.19 implies the model is significant. There is only a $0.01 \%$ chance that a "Model F-Value" this large could occur due to noise. Values of "Prob $>$ F" less than 0.10 indicate model terms are significant. In this case $\mathrm{A}, \mathrm{B}, \mathrm{AB}, \mathrm{A}^{2}, \mathrm{~B}^{2}$ are significant model terms. Values greater than 0.1000 indicate the model terms are not significant. The "Lack of Fit F-value" of 3.25 implies the Lack of Fit is not significant relative to the pure error. There is a $14.23 \%$ chance that a "Lack of Fit F-value" this large could occur due to noise.

\begin{tabular}{lr}
\hline \multicolumn{2}{c}{ Fitting Statistics } \\
\hline Standard deviation & 6.87 \\
Mean & 179.66 \\
Coefficient of variance (\%) & 3.82 \\
PRESS & 1811.40 \\
$\mathrm{R}^{2}$ & 0.9970 \\
Adjusted R & \\
Predicted R & 0.9949 \\
Adequate Precision & 0.9837 \\
\hline
\end{tabular}

The predicted $\mathrm{R}^{2}$ of 0.9837 is in reasonable agreement with the adjusted $\mathrm{R}^{2}$ of 0.9949 . Adequate precision measures the signal to noise ratio. Ideally, a ratio greater than 4 is desirable. Model ratio of 56.671 indicates an adequate signal. Thus, this model can be used to navigate the design space. 


\section{Supporting information S2: Polydispersity index (PDI)}

The software suggested the quadratic model, for the PDI response based on the statistical significance and model maximizing the adjusted $\mathrm{R}^{2}$ and the predicted $\mathrm{R}^{2}$.

\begin{tabular}{ccccc}
\hline Source & $\begin{array}{c}\text { Sequential } \\
\text { p-value }\end{array}$ & $\begin{array}{c}\text { Lack of } \\
\text { Fit p-value }\end{array}$ & $\begin{array}{c}\text { Adjusted R- } \\
\text { Squared }\end{array}$ & $\begin{array}{c}\text { Predicted R- } \\
\text { Squared }\end{array}$ \\
\hline Linear & 0.0005 & 0.0157 & 0.7334 & 0.6291 \\
2FI & 0.3527 & 0.0141 & 0.7323 & 0.6138 \\
Quadratic & $\mathbf{0 . 0 0 0 3}$ & $\mathbf{0 . 5 3 9 1}$ & $\mathbf{0 . 9 6 7 1}$ & $\mathbf{0 . 9 2 5 2}^{¥}$ \\
Cubic & 0.3033 & 0.8446 & 0.9714 & 0.9730 \\
\hline
\end{tabular}

suggested

Analysis of variance table for Response Surface Quadratic Model

\begin{tabular}{llllll} 
Source & Sum of Squares & df & Mean Square & F Value & Prob $>$ F \\
\hline
\end{tabular}




\begin{tabular}{cccccc}
\hline & & & & & p-value \\
\hline Model & 0.1935 & 5 & 0.0387 & 71.68 & $<0.0001^{¥}$ \\
A-A & 0.0000 & 1 & 0.0000 & 0.01 & 0.9141 \\
B-B & 0.0058 & 1 & 0.0058 & 10.65 & 0.0138 \\
AB & 0.0042 & 1 & 0.0042 & 7.82 & 0.0266 \\
$\mathrm{~A}^{\wedge} 2$ & 0.0206 & 1 & 0.0206 & 38.08 & 0.0005 \\
$\mathrm{~B}^{\wedge} 2$ & 0.0228 & 1 & 0.0228 & 42.28 & 0.0003 \\
Residual & 0.0038 & 7 & 0.0005 & & \\
Lack of Fit & 0.0015 & 3 & 0.0005 & 0.84 & $0.5391^{\text {f }}$ \\
Pure Error & 0.0023 & 4 & 0.0006 & & \\
Cor Total & 0.1973 & 12 & & & \\
\hline
\end{tabular}

Where, A: Drug:Polymer ratio (w/w), B: Solvent:Non-Solvent ratio (v/v), ${ }^{¥}$ significant and ${ }^{\mathfrak{E}}$ not significant

The Model F-value of 71.68 implies the model is significant. There is only a $0.01 \%$ chance that a "Model F-Value" this large could occur due to noise. Values of "Prob > F" less than 0.10 indicate model terms are significant. In this case $\mathrm{A}, \mathrm{B}, \mathrm{AB}, \mathrm{A}^{2}, \mathrm{~B}^{2}$ are significant model terms. Values greater than 0.1000 indicate the model terms are not significant. The "Lack of Fit F-value" of 0.84 implies the Lack of Fit is not significant relative to the pure error. There is a $53.91 \%$ chance that a "Lack of Fit F-value" this large could occur due to noise.

\begin{tabular}{lr}
\hline \multicolumn{2}{c}{ Fitting Statistics } \\
\hline Standard deviation & 0.02 \\
Mean & 0.31 \\
Coefficient of variance (\%) & 7.51 \\
PRESS & 0.01 \\
$\mathrm{R}^{2}$ & 0.9808 \\
Adjusted R $^{2}$ & 0.9672 \\
Predicted ${ }^{2}$ & 0.9253 \\
Adequate Precision & 26.18 \\
\hline
\end{tabular}

The predicted $\mathrm{R}^{2}$ of 0.9253 is in reasonable agreement with the adjusted $\mathrm{R}^{2}$ of 0.9672 . Adequate precision measures the signal to noise ratio. Ideally, a ratio greater than 4 is desirable. Model ratio of 26.183 indicates an adequate signal. Thus, this model can be used to navigate the design space. 


\section{Supporting information S3: \% Drug loading (DL)}

The software suggested the quadratic model, for the $\% \mathrm{DL}$ response based on the statistical significance and model maximizing the adjusted $\mathrm{R}^{2}$ and the predicted $\mathrm{R}^{2}$.

\begin{tabular}{ccccc}
\hline Source & $\begin{array}{c}\text { Sequential } \\
\text { p-value }\end{array}$ & $\begin{array}{c}\text { Lack of } \\
\text { Fit p-value }\end{array}$ & $\begin{array}{c}\text { Adjusted R- } \\
\text { Squared }\end{array}$ & $\begin{array}{c}\text { Predicted R- } \\
\text { Squared }\end{array}$ \\
\hline Linear & 0.0059 & 0.0086 & 0.5706 & 0.1746 \\
2FI & 0.5351 & 0.0070 & 0.5439 & 0.1955 \\
Quadratic & $\mathbf{0 . 0 0 0 1}$ & $\mathbf{0 . 3 9 9 4}$ & $\mathbf{0 . 9 5 3 5}$ & $\mathbf{0 . 8 8 4 8}$ \\
Cubic & 0.9476 & 0.1297 & 0.9363 & 0.1196 \\
\hline
\end{tabular}

¥suggested

Analysis of variance table for Response Surface Quadratic Model 


\begin{tabular}{cccccc}
\hline Source & Sum of Squares & df & Mean Square & F Value & $\begin{array}{c}\text { Prob }>\text { F } \\
\text { p-value }\end{array}$ \\
\hline Model & 115.52 & 5 & 23.10 & 50.21 & $<0.0001^{\ddagger}$ \\
A-A & 25.32 & 1 & 25.32 & 55.02 & 0.0001 \\
B-B & 0.93 & 1 & 0.93 & 2.01 & 0.199 \\
AB & 1.88 & 1 & 1.88 & 4.08 & 0.0832 \\
$\mathrm{~A}^{\wedge} 2$ & 12.05 & 1 & 12.05 & 26.18 & 0.0014 \\
$\mathrm{~B}^{\wedge} 2$ & 17.52 & 1 & 17.52 & 38.07 & 0.0005 \\
Residual & 3.22 & 7 & 0.46 & & \\
Lack of Fit & 1.57 & 3 & 0.52 & 1.26 & $0.3994^{£}$ \\
Pure Error & 1.65 & 4 & 0.41 & & \\
Cor Total & 118.74 & 12 & & & \\
\hline : Drug:Polymer ratio $(\mathrm{w} / \mathrm{w})$, B: Solvent:Non-Solvent ratio $(\mathrm{v} / \mathrm{v}){ }^{¥}{ }^{\ddagger}$ significant and ${ }^{£}$ not significant
\end{tabular}

Where, A: Drug:Polymer ratio (w/w), B: Solvent:Non-Solvent ratio (v/v), ${ }^{¥}$ significant and ${ }^{\mathfrak{f}}$ not significant

The Model F-value of 50.21 implies the model is significant. There is only a $0.01 \%$ chance that a "Model F-Value" this large could occur due to noise. Values of "Prob > F" less than 0.10 indicate model terms are significant. In this case $\mathrm{A}, \mathrm{B}, \mathrm{AB}, \mathrm{A}^{2}, \mathrm{~B}^{2}$ are significant model terms. Values greater than 0.1000 indicate the model terms are not significant. The "Lack of Fit F-value" of 1.26 implies the Lack of Fit is not significant relative to the pure error. There is a $39.94 \%$ chance that a "Lack of Fit F-value" this large could occur due to noise.

\begin{tabular}{lr}
\hline \multicolumn{2}{c}{ Fitting Statistics } \\
\hline Standard deviation & 0.68 \\
Mean & 16.29 \\
Coefficient of variance (\%) & 4.16 \\
PRESS & 13.67 \\
$\mathrm{R}^{2}$ & 0.9729 \\
Adjusted R & \\
Predicted $\mathrm{R}^{2}$ & 0.9535 \\
Adequate Precision & 0.8848 \\
\hline
\end{tabular}

The predicted $\mathrm{R}^{2}$ of 0.8848 is in reasonable agreement with the adjusted $\mathrm{R}^{2}$ of 0.9535 . Adequate precision measures the signal to noise ratio. Ideally, a ratio greater than 4 is desirable. Model ratio of 27.209 indicates an adequate signal. Thus, this model can be used to navigate the design space. 


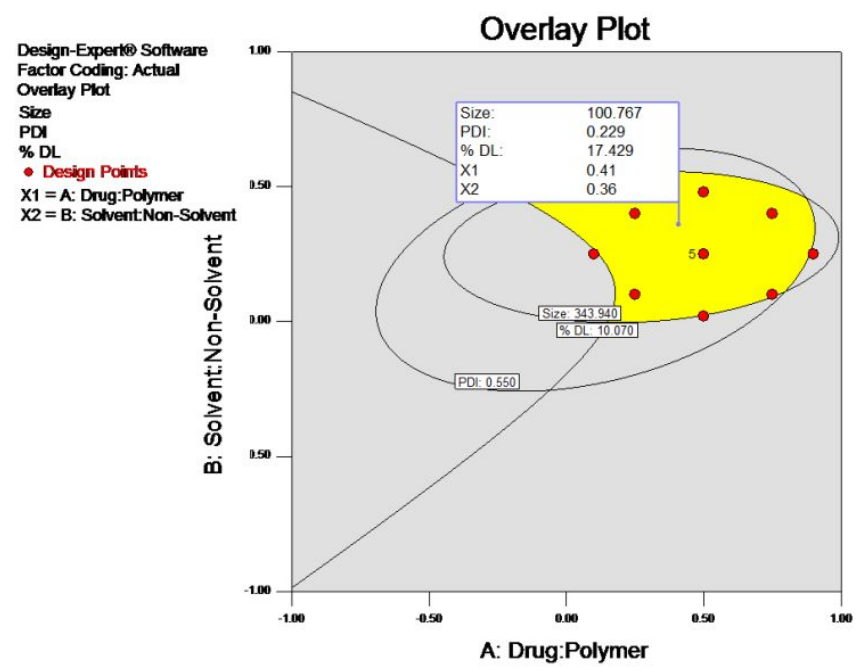

Figure S3 Optimized overlay plot for design

Fig. S3 describes an overlay plot encompassing two regions viz., yellow region denoting the optimal design space region with feasible response and grey region is the area where response did not fit the desired product criteria. 


\section{Supplementary Information, S4: Residual Organic Content Estimation}

As per the procedure organic solvents used were acetonitrile and triethyl amine. The benzyl alcohol was selected as a sample diluent due to the reproducibility, higher solubility and best baseline with no interference at the retention times of the residual organic solvents of interest. The GC system consisted of Shimadzu GC-2010 Plus equipped with FID detector and Shimadzu HS-10 auto sampler was used for sample analysis Column used for the analysis was Rtx-624 (30 m X 0.32 mm ID X $1.8 \mu \mathrm{m}$ ) capillary column. Sample solution was prepared by dissolving about $500 \mathrm{mg}$ of lyophilized formulation with $5 \mathrm{~mL}$ of extracting solvents in a $20-\mathrm{mL}$ headspace $\mathrm{GC}$ vial. All vials were capped and crimped immediately after samples were added.

Other chromatographic parameters are listed as below

\section{Gas Chromatograph Operating Conditions}

\begin{tabular}{|l|c|l|}
\hline Instrument Details & $:$ & Shimadzu GC-2010 Plus with HS-10 Injector \\
\hline Column Details & $:$ & Rtx-624 (30 m X $0.32 \mathrm{~mm}$ ID X 1.8 $\mu \mathrm{m})$ \\
\hline Injection Mode & $:$ & Split \\
\hline Injection Port Temp & $:$ & $180^{\circ} \mathrm{C}$ \\
\hline Flow Control Mode & $:$ & Linear Velocity \\
\hline Pressure & $:$ & $7.2 \mathrm{psi}$ \\
\hline
\end{tabular}




\begin{tabular}{|c|c|c|c|c|}
\hline Total Flow & : & \multicolumn{3}{|c|}{$91.5 \mathrm{~mL} / \mathrm{min}$} \\
\hline Column Flow & : & \multicolumn{3}{|c|}{$1.50 \mathrm{~mL} / \mathrm{min}$} \\
\hline Linear Velocity & : & \multicolumn{3}{|c|}{$22.3 \mathrm{~cm} / \mathrm{sec}$} \\
\hline Purge Flow & : & \multicolumn{3}{|c|}{$0.0 \mathrm{~mL} / \mathrm{min}$} \\
\hline Split Ratio & : & \multicolumn{3}{|l|}{60.0} \\
\hline FID Temp. & : & \multicolumn{3}{|l|}{$260^{\circ} \mathrm{C}$} \\
\hline Carrier gas & : & \multicolumn{3}{|c|}{ Nitrogen } \\
\hline \multicolumn{5}{|l|}{ Oven Programming } \\
\hline \multirow[t]{3}{*}{ Column Oven program } & : & Rate & $\begin{array}{l}\text { Temperature } \\
\left({ }^{\circ} \mathrm{C}\right)\end{array}$ & $\begin{array}{l}\text { Hold Time } \\
(\mathrm{min})\end{array}$ \\
\hline & & - & 50.0 & 6.00 \\
\hline & & 50.00 & 220.0 & 8.00 \\
\hline Run Time & & \multicolumn{3}{|c|}{$17.40 \mathrm{~min}$} \\
\hline
\end{tabular}

\section{HS-10 Parameters}

\begin{tabular}{|l|l|l|}
\hline Oven Temp & $:$ & $95.0^{\circ} \mathrm{C}$ \\
\hline Sample Line Temp & $:$ & $110.0^{\circ} \mathrm{C}$ \\
\hline Transfer Line Temp & $:$ & $120.0^{\circ} \mathrm{C}$ \\
\hline Shaking Level & $:$ & 3 \\
\hline Pressurization Gas Pressure & $:$ & 10 Psi \\
\hline Equilibrium Time & $:$ & $30.00 \mathrm{~min}$ \\
\hline Pressurizing Time & $:$ & $1.00 \mathrm{~min}$ \\
\hline Pressure Equilib Time & $:$ & $0.20 \mathrm{~min}$ \\
\hline Load Time & $:$ & $0.50 \mathrm{~min}$ \\
\hline Load Equilib Time & $:$ & $0.20 \mathrm{~min}$ \\
\hline Injection Time & $:$ & $1.00 \mathrm{~min}$ \\
\hline
\end{tabular}


\begin{tabular}{|l|l|l|}
\hline GC Cycle Time & $:$ & $23.00 \mathrm{~min}$ \\
\hline
\end{tabular}

$<$ Chromatogram>

$\mathrm{mV}$

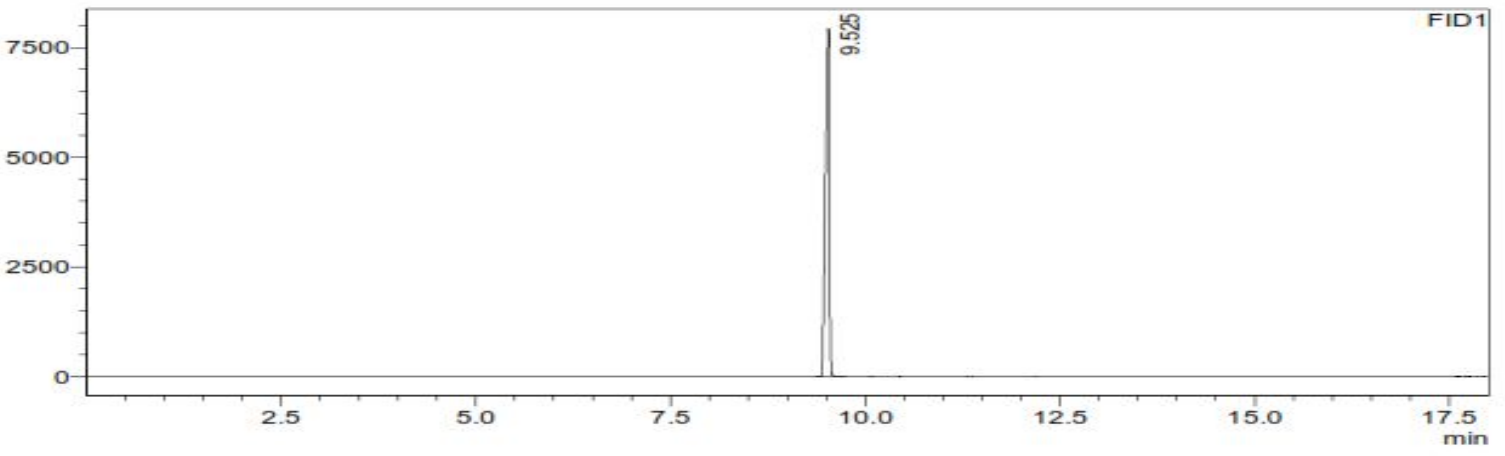

Blank Chromatogram

\section{$<$ Chromatogram>}

$\mathrm{mV}$

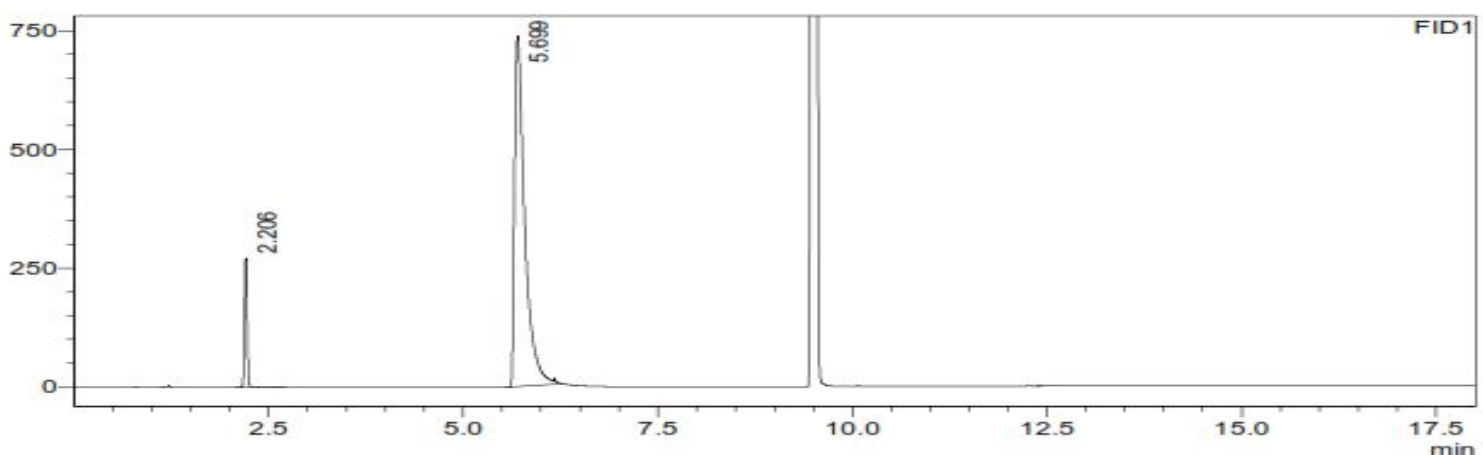

Standard chromatogram spiked with 2000ppm acetonitrile (Rt: $2.2 \mathrm{~min}$ ) and 5000ppm trimethyl amine (Rt: $5.6 \mathrm{~min})$

$<$ Chromatogram>

$\mathrm{mV}$

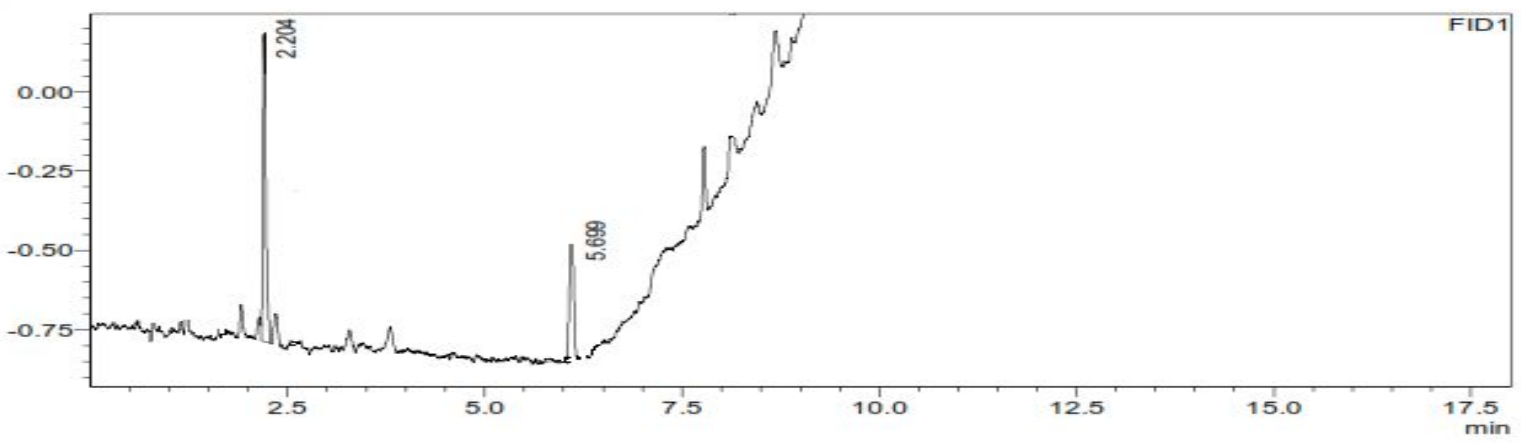

Chromatogram for lyophilized polymeric nanoformulation

The residual organic content of acetonitrile and triethylamine in the lyophilized polymeric nanoparticles (D1-NPs) was found to be $40.48 \pm 9.24 \mathrm{ppm}$ and $24.92 \pm 6.51$ respectively. 


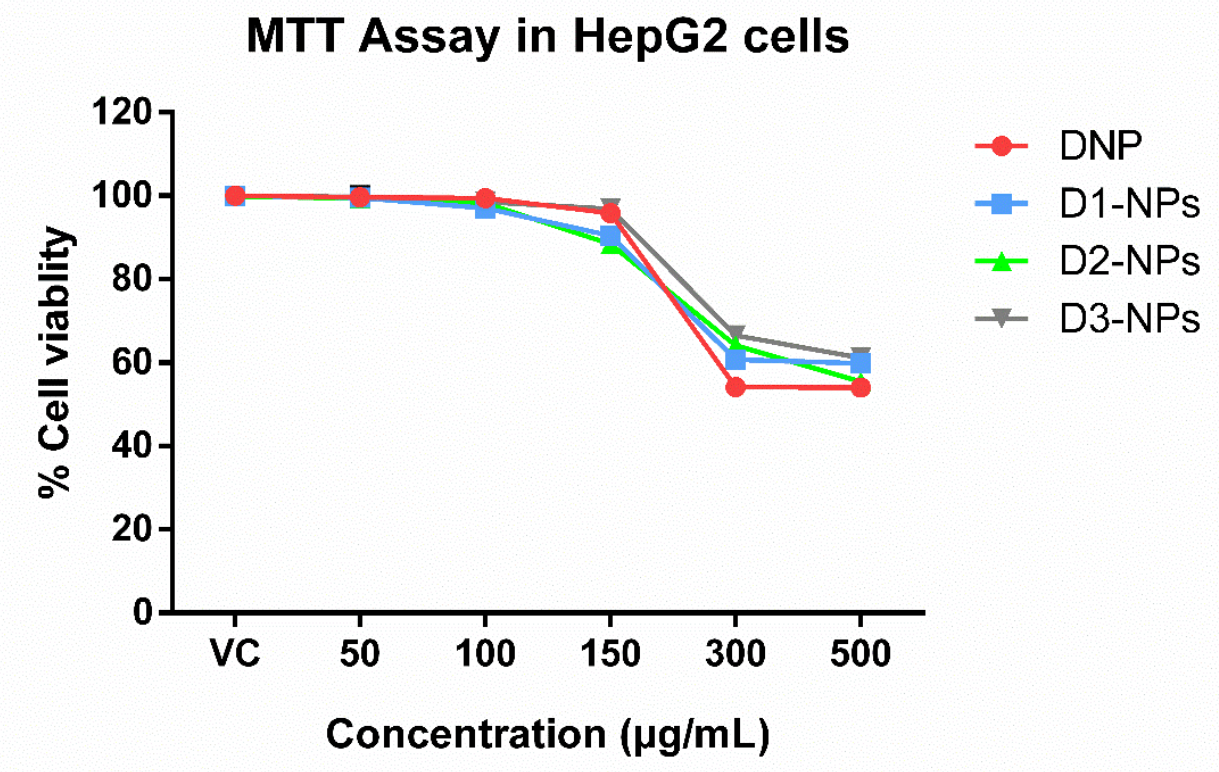

Fig. S4 MTT cell viability assay in HepG2 cells

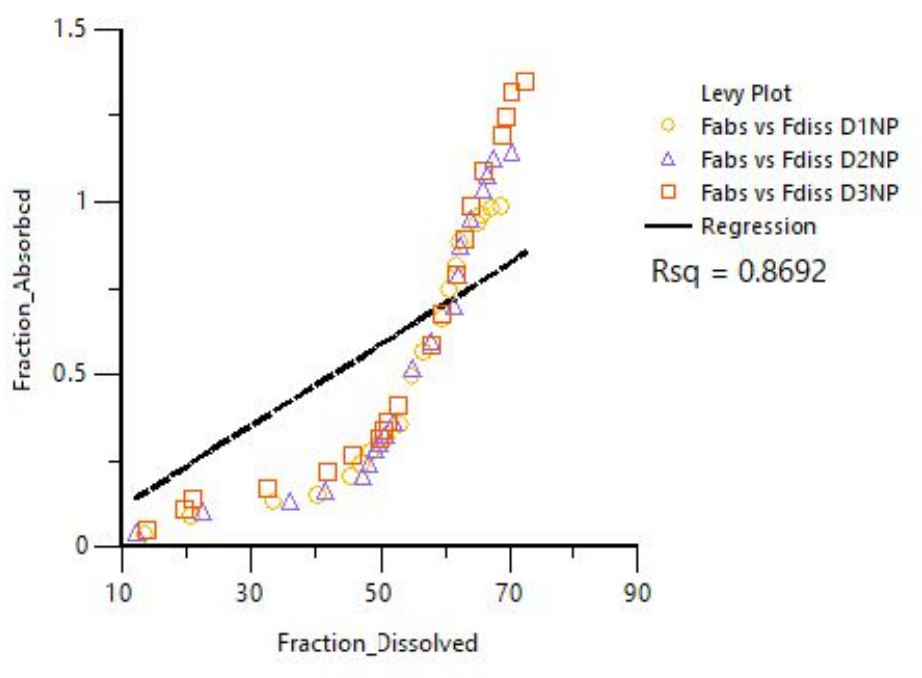


Fig. S5 Fraction dissolved versus fraction absorbed correlation graph generated by Phoenix software

Table S3: IVIVC internal validation correlation 


\begin{tabular}{|c|c|c|c|}
\hline Parameter & Predicted & Observed & \% PE \\
\hline$C_{\max }$ & 437.76 & 484.61 & -9.61 \\
\hline AUC & 14980.87 & 16532.19 & -9.38 \\
\hline
\end{tabular}




\section{$\underline{\text { Supplementary Information, S5: Biodistribution }}$}
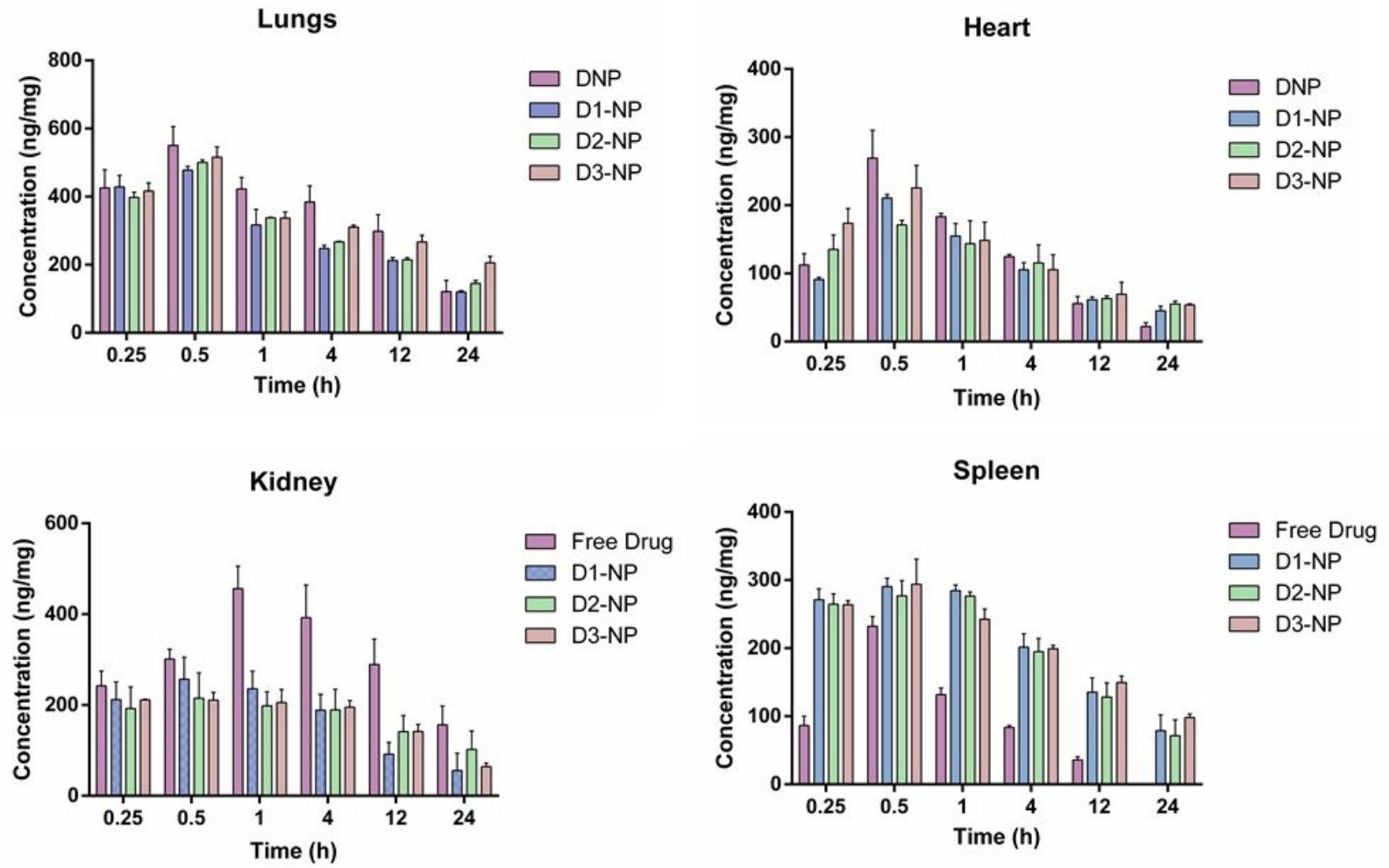